\title{
Mechanism of phthalate ester hydrolysis in water and in cyclodextrin mediated reactions
}

\author{
Gabriel O. Andrés and Rita H. de Rossi* \\ Instituto de Investigaciones en Físico Química de Córdoba (INFIQC), Facultad de Ciencias \\ Químicas, Departamento de Química Orgánica, Universidad Nacional de Córdoba, Ciudad \\ Universitaria, 5000 Córdoba, Argentina \\ E-mail: ritah@dqo.fcq.unc.edu.ar
}

Dedicated to Prof. Edmundo Rúveda and Roberto A. Rossi

(received 01 Jul 03; accepted 12 Aug 03; published on the web 19 Aug 03)

\begin{abstract}
The kinetics of the hydrolysis of benzyl hydrogen phthalate $\mathbf{1}$ was studied at $\mathrm{OH}$ - concentration within 0.05 and $0.5 \mathrm{M}$. The reaction does not manifest appreciable intramolecular catalysis. The base catalyzed rate constant is about two orders of magnitude faster than the value predicted by the Brönsted plot defined by aryl hydrogen phthalate esters. In the presence of hydroxypropyl- $\beta$ cyclodextrin (HPCD) at $\mathrm{NaOH}=0.45 \mathrm{M}$ and at $\mathrm{pH}=12.8$ the observed rate constant for the hydrolysis decreases as the HPCD concentration increases in a non-linear fashion. The kinetic results are interpreted in terms of the formation of an inclusion complex of the ionized substrate $\mathrm{K}_{\mathrm{CD}}{ }^{\mathrm{A}}$, with HPCD. In this complex the carboxylate group forms hydrogen bonds with the hydroxyl groups at the rim of the cyclodextrin cavity and the ionised group of the cyclodextrin is kept away from the reaction center due to electrostatic repulsion.
\end{abstract}

Keywords: Ester hydrolysis mechanism, intramolecular catalysis, cyclodextrin

\section{Introduction}

The study of intramolecular catalysis in model systems gives important information about enzyme mechanisms. ${ }^{1}$ It has been shown that the factors that favour the formation of the cyclic intermediate have enormous influence on the reaction rates. ${ }^{1 \mathrm{c}, 2}$ Cyclodextrins, which are cyclic oligomers of $\alpha$-D-glucose have a well defined cavity ${ }^{3}$ and have been frequently used as microreactors which can catalyze or inhibit organic reactions by including the substrate in their cavity. ${ }^{4}$ Intramolecular reactions are very much dependent on the relative position of the reacting groups and the time that they are at the proper distance for reaction. ${ }^{5}$ Inclusion in the cavity of 
cyclodextrin may change the geometry of the substrate and so make intramolecular reactions more favourable ${ }^{6}$ or more unfavourable than the reactions of the free substrate.

The intramolecular reaction of monoaryl phthalate esters is strongly dependent on the pKa of the leaving group $\left(\beta_{\mathrm{lg}}=-1.15\right)^{7}$. This result can be attributed either to a mechanism involving a tetrahedral intermediate, which has the leaving group departure as the rate determining step, or to a concerted mechanism for carboxylate addition and phenol departure. For a stepwise mechanism, a curved Brönsted plot is expected when the range of $\mathrm{pK}_{\mathrm{a}}$ of the leaving groups is wide enough. ${ }^{8}$ We therefore considered of interest a study of the kinetic of hydrolysis of benzyl hydrogen phthalate $\mathbf{1}$ in water. Unfortunately this ester is too unreactive under conditions where the intramolecular reaction can compete with the second order rate constant for the reaction of $\mathrm{OH}^{-}$with the ester. On the other hand, the results for the kinetics of the hydrolysis of this compound in basic solution, gives interesting information regarding the hydrolysis mechanism.

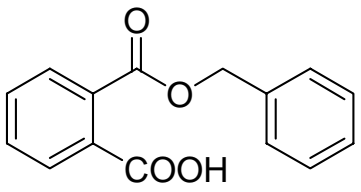

1

We also have studied the reaction in the presence of cyclodextrin because $\mathbf{1}$ and phenyl hydrogen phthalate have similar structural characteristic and they should form similar complexes with $\beta$-cyclodextrin. The addition of cyclodextrin significantly decreases the rate of hydrolysis due to the formation of an inclusion compound with an unfavourable structure for the intramolecular reaction of the substrate with the ionized hydroxyl group of cyclodextrin. On the other hand, the reaction of an external $\mathrm{OH}^{-}$is also inhibited for steric as well as electrostatic reasons. As a result the substrate is very resistant to basic ester hydrolysis.

\section{Results and Discussion}

Unless otherwise mentioned, all the kinetic studies were carried out in water containing $3.85 \%$ $\mathrm{v} / \mathrm{v}$ acetonitrile (ACN) at $25{ }^{\circ} \mathrm{C}$. At $\mathrm{pH} 1.00$ and 8.00 , we did not see any reaction in 7 days indicating that the intramolecular catalyzed reaction has a rate constant smaller than $10^{-6} \mathrm{~s}^{-1}$. The reaction rate for the hydrolysis reaction was determined under pseudo first order conditions using variable $\mathrm{OH}^{-}$concentration in the range 0.05 to $0.5 \mathrm{M}$ (Table 1 ).

A plot of the observed rate constant vs $\mathrm{OH}^{-}$concentration (not shown) is linear and from the slope, the second order rate constant for the hydrolysis reaction was calculated as (3.13 \pm 0.06$) \times 10^{-3} \mathrm{M}^{-1} \mathrm{~s}^{-1}$. The intercept of his plot is zero within experimental error confirming that the intramolecular catalyzed reaction is very inefficient. 
Table 1. Hydrolysis of benzyl hydrogen phthalate as a function of hydroxide ion concentration ${ }^{\mathrm{a}}$

\begin{tabular}{ll}
\hline$[\mathrm{NaOH}], 10^{-2} \mathrm{M}$ & $\mathrm{k}_{\mathrm{obs}}, 10^{-4} \mathrm{~s}^{-1 \mathrm{~b}}$ \\
\hline 5 & $1.496 \pm 0.007$ \\
10 & $3.01 \pm 0.02$ \\
20 & $6.4 \pm 0.4$ \\
30 & $8.8 \pm 0.2$ \\
40 & $12.35 \pm 0.07$ \\
48 & $15.0 \pm 0.3$ \\
50 & $15.2 \pm 0.8$ \\
\hline
\end{tabular}

a The reactions were measured at $278 \mathrm{~nm}$. The solvent contains $3.85 \%$ of acetonitrile. Temperature $25{ }^{\circ} \mathrm{C}$, ionic strength $0.5 \mathrm{M}\left(\mathrm{NaCl}\right.$ as compensating electrolyte). ${ }^{\mathrm{b}}$ The errors are standard deviations of two determinations.

In order to get more insight into the mechanism of the hydrolysis reaction of this ester, we have determined the second order rate constants for the base catalyzed hydrolysis of Z-aryl hydrogen phthalates $(\mathrm{Z}=\mathrm{p}-\mathrm{Me}, \mathrm{m}-\mathrm{Me}, \mathrm{H}, \mathrm{p}-\mathrm{Cl}$ and $\mathrm{m}-\mathrm{Cl})$. The data are collected in Table 2. For comparison purposes, data for the hydrolysis of aryl benzoate esters are also shown in Table 2. It can be seen that the carboxylate group decreases the rate of hydrolysis by about a factor of two. With the data for the hydrolysis of aryl hydrogen phthalates (Table 2) a Brönsted plot can be drawn, Figure 1, and from the slope the $\beta_{\mathrm{lg}}=-0.68$ is obtained.

Table 2. Second order rate constants for the hydrolysis of Z-aryl hydrogen phthalates ${ }^{\mathrm{a}}$

\begin{tabular}{|c|c|c|c|}
\hline \multirow{2}{*}{$\mathrm{Z}$} & Phthalate $^{\mathrm{b}}$ & Benzoate & \multirow{2}{*}{$r^{d}$} \\
\hline & $\mathrm{k}_{\mathrm{OH}}, 10^{-2} \mathrm{~s}^{-1} \mathrm{M}^{-1}$ & $\mathrm{k}_{\mathrm{OH}}, 10^{-2} \mathrm{~s}^{-1} \mathrm{M}^{-1 \mathrm{c}}$ & \\
\hline p-Me & $1.92 \pm 0.09$ & 3.32 & 0.578 \\
\hline m-Me & $2.5 \pm 0.2$ & & \\
\hline $\mathrm{H}$ & $3.1 \pm 0.1$ & 5.60 & 0.554 \\
\hline $\mathrm{p}-\mathrm{Cl}$ & $6.1 \pm 0.5$ & 12.42 & 0.487 \\
\hline $\mathrm{m}-\mathrm{Cl}$ & $14.5 \pm 0.7$ & & \\
\hline
\end{tabular}

a The reactions were measured at $278 \mathrm{~nm}$. The solvent contains $3.85 \%$ of acetonitrile. Temperature $25^{\circ} \mathrm{C}$, ionic strength $0.5 \mathrm{M}\left(\mathrm{NaCl}\right.$ as compensating electrolyte). ${ }^{\mathrm{b}}$ The errors are standard deviations of at least 5 determinations. ' Taken from Kirsch, J.F.; Clewell,W.; Simon, A. J. Org. Chem. 1968, 33, 127. ${ }^{\text {d }}$ Ratio between the rate constants for phthalate and benzoate. 


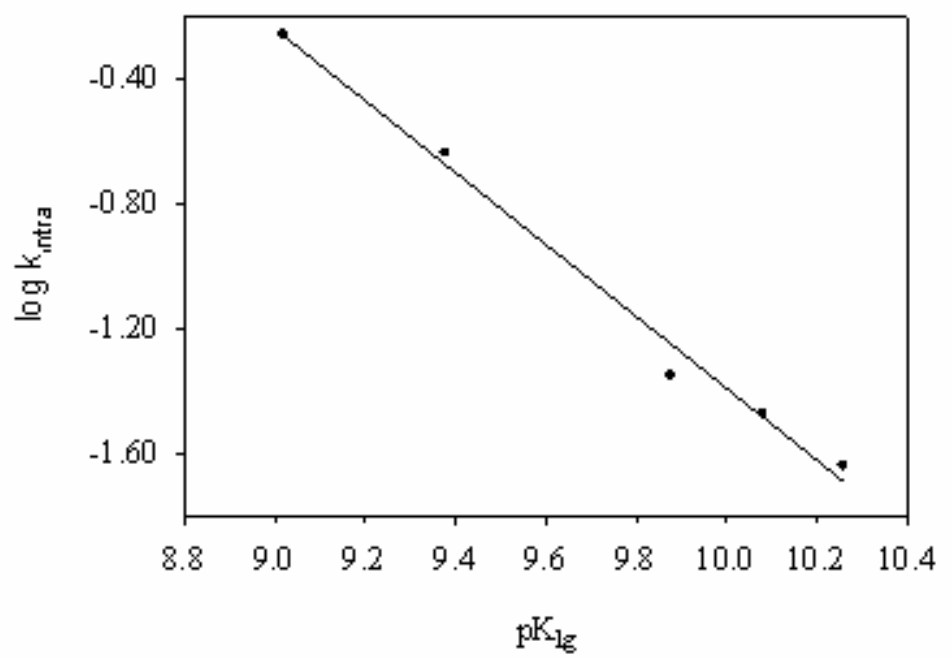

Figure 1. Brönsted plot for the basic hydrolysis of Z-aryl hydrogen phthalates. The pKa of the phenols were taken from Jencks, W. P.; Gildrist, M. J. Am. Chem. Soc. 1968, 90, 2622 and from .CRC Handbook of Biochemistry and Molecular Biology, Easman, G.. A. Editor, $3^{\text {rd }}$ Edition, Cleveland, Ohio, CRC Press, 1977.

Considering that the $\mathrm{pK}_{\mathrm{a}}$ of benzyl alcohol can be estimated as $14.3,{ }^{9}$ we calculate the second order rate constant for the hydrolysis of $\mathbf{1}$ as $2.7 \times 10^{-5} \mathrm{M}^{-1} \mathrm{~s}^{-1}$. This value is about two orders of magnitude smaller than the experimental value. It is important to notice that the Brönsted plot for the reaction of hydroxide ion with substituted phenyl acetates fall one order of magnitude bellow that for the reaction with acetates of substituted alcohols. ${ }^{10}$

The discrepancy between the calculated and observed values may be explained taking into account relevant discussion existent in the literature which indicate that for the hydrolysis of aryl esters there is no barrier for the expulsion of the aryloxide leaving group, therefore the reaction can be considered to be concerted. On the other hand, for the hydrolysis of esters with poorer leaving groups, the mechanism of hydrolysis involves a tetrahedral intermediate. ${ }^{11,12,13,14}$

The hydrolysis reaction of $\mathbf{1}$ was studied at $\mathrm{pH}=12.80$ and at $\mathrm{NaOH}=0.45 \mathrm{M}$ in the presence of variable concentration of hydroxypropyl- $\beta$-cyclodextrin (HPCD) (Table 3). This compound is a derivative of $\beta$-cyclodextrin, that have some of the primary and secondary hydroxyl groups substituted with hydroxypropyl group. The HPCD that we used has an average degree of substitution of 5.9. The chemical behaviour of HPCD is similar to that of the unsubstituted $\beta$ cyclodextrin. ${ }^{15}$

In all cases the reaction is inhibited by hydroxypropyl- $\beta$-cyclodextrin and the plot of $k_{\text {obs }}$ vs HPCD concentration is non-linear (Figure 2 is representative). On the other hand alpha and gamma cyclodextrin do not affect the rate, which point to the importance of the size of the cavity for the inhibition. 
Table 3. Effect of HPCD on the rate of hydrolysis of benzyl hydrogen phthalate ${ }^{a}$

\begin{tabular}{lll}
\hline$[\mathrm{HP}-\beta-\mathrm{CD}], 10^{-3} \mathrm{M}$ & $\begin{array}{l}\mathrm{pH}=12.80 \\
\mathrm{k}_{\mathrm{obs}}, 10^{-4} \mathrm{~s}^{-1}\end{array}$ & $\begin{array}{l}{[\mathrm{NaOH}]=0.45 \mathrm{M}} \\
\mathrm{k}_{\mathrm{obs}}, 10^{-4} \mathrm{~s}^{-1}\end{array}$ \\
\hline 0.0 & $3.37 \pm 0.05$ & $13.8 \pm 0.4$ \\
1.0 & $3.32 \pm 0.07$ & \\
2.5 & & $12.3 \pm 0.4$ \\
3.0 & $3.12 \pm 0.01$ & \\
5.0 & $2.84 \pm 003$ & $10.8 \pm 0.2$ \\
7.0 & $2.64 \pm 0.07$ & \\
10.0 & $2.29 \pm 0.06$ & $9.32 \pm 0.03$ \\
15.0 & $2.16 \pm 0.04$ & $7.9 \pm 0.1$ \\
20.0 & $1.61 \pm 0.03$ & $7.03 \pm 0.05$ \\
25.0 & & $6.27 \pm 0.04$ \\
30.0 & $1.36 \pm 0.02$ & $5.6 \pm 0.2$ \\
\hline
\end{tabular}

${ }^{\mathrm{a}}$ The solvent contain $3.85 \%$ of acetonitrile. Temperature $25{ }^{\circ} \mathrm{C}$, ionic strength $0.5 \mathrm{M}(\mathrm{NaCl}$ as compensating electrolyte), error are standard deviations of at least two determinations.

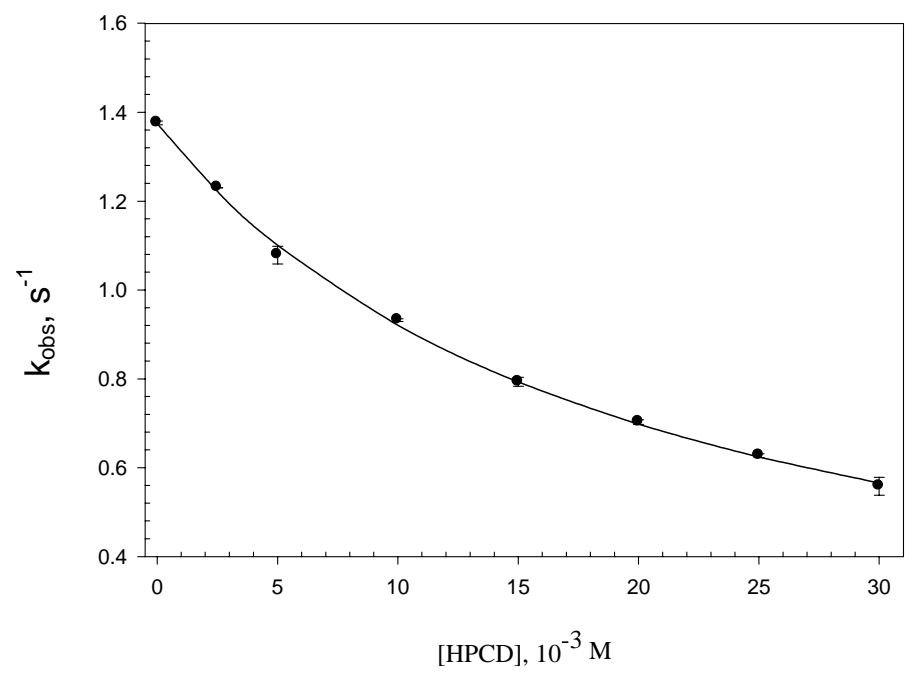

Figure 2. Effect of HPCD on the hydrolysis of $\mathbf{1}$ at $25^{\circ} \mathrm{C}$. $\mathrm{NaOH}=0.45 \mathrm{M}$.

In order to determine whether the substrate is associated with the cavity of cyclodextrin, the reaction was studied in the presence of alcohols that have been shown to compete for the cavity of cyclodextrin. ${ }^{16}$ The data are shown in Table 4 . We can see that with cyclohexanol, that has the highest association constant, the rate increases and this is consistent with displacement of the substrate from the cavity. 
Table 4. Observed rate constant for the hydrolysis of $\mathbf{1}$ in the presence of several alcohols ${ }^{\mathrm{a}}$

\begin{tabular}{lll}
\hline Alcohol $\left(\mathrm{K}, \mathrm{M}^{-1}\right)^{\mathrm{b}}$ & Concentration, $10^{-3} \mathrm{M}$ & $\mathrm{k}_{\mathrm{obs}}, 10^{-4} \mathrm{~s}^{-1}$ \\
\hline 1-Propanol (4.47) & 100.0 & $1.16 \pm 0.03$ \\
2-Propanol (2.57) & 102.1 & $1.00 \pm 0.03$ \\
t-Butanol & 100.9 & $1.38 \pm 0.08$ \\
Cyclohexanol (688) & 11.3 & $1.32 \pm 0.02$ \\
Cyclohexanol & 50.9 & $2.19 \pm 0.04$ \\
Cyclohexanol & 103.3 & $2.45 \pm 0.04$ \\
c & & $3.01 \pm 0.02$ \\
d & & $1.05 \pm 0.05$ \\
\hline
\end{tabular}

${ }^{a}[\mathrm{HPCD}]=0.03 \mathrm{M}$ (unless otherwise noticed), $[\mathrm{NaOH}]_{\mathrm{eff}}=0.10 \mathrm{M}$. The solvent contains $3.85 \%$ of acetonitrile. Temperature $25{ }^{\circ} \mathrm{C}$, ionic strength $0.5 \mathrm{M}(\mathrm{NaCl}$ as compensating electrolyte), error are standard deviations of at lest two determinations. ${ }^{\mathrm{b}}$ Values within bracket are equilibrium constants for the association with $\beta$-cyclodextrin taken from Rekharsky, M.V.; Inoue,Y. Chem Rev. 1998, 98, 1875. ${ }^{\mathrm{c}}$ Reaction without HPCD and without alcohol. ${ }^{\mathrm{d}}$ Reaction without alcohol.

Based on all these data we suggest the mechanism shown in Scheme 1. The anion of the substrate associates with cyclodextrin probably through the aryl ring of the benzylic alcohol leaving group (see below) and the associated compound react at slower rate than the free compound. It should be noticed that HPCD has a $\mathrm{pK}_{\mathrm{a}}$ of about $12.2^{17}$ so under the conditions of this study is ionized

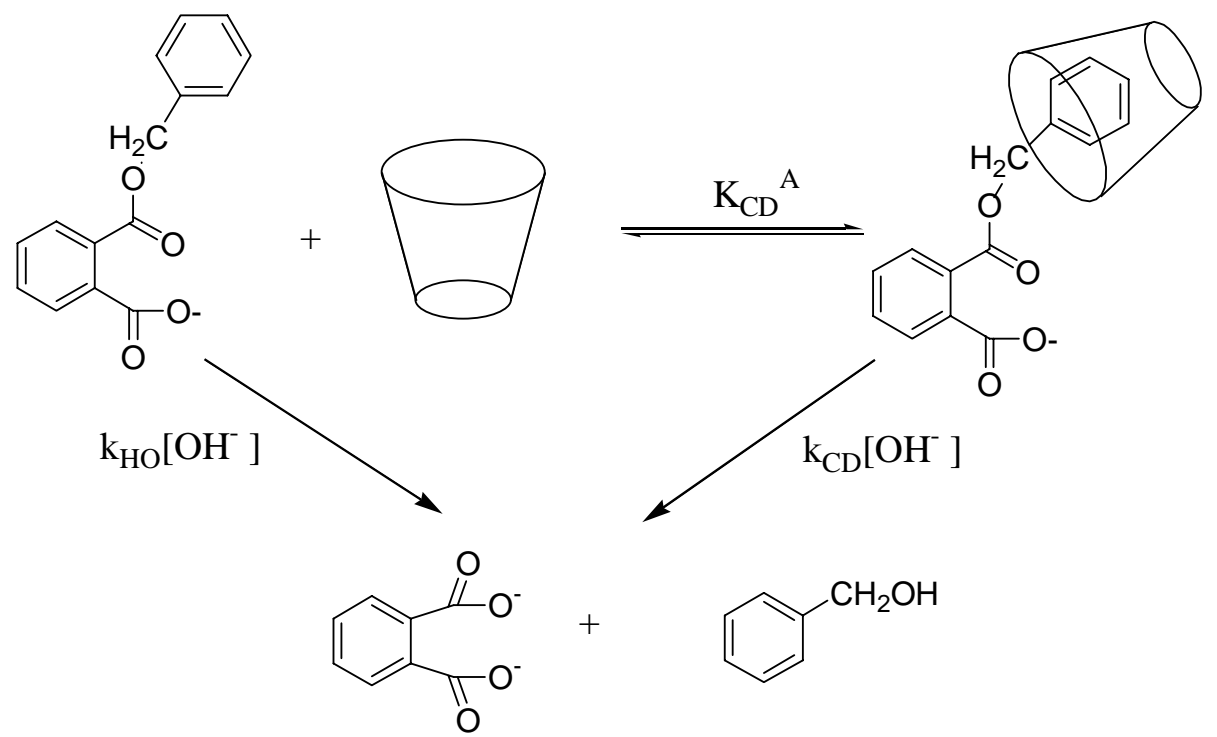

\section{Scheme 1}


The observed rate constant for Scheme 1 is given by equation 1 were $\mathrm{k}_{\mathrm{CD}}$ is the rate constant of the included substrate, $K_{C D}{ }^{A}$ is the association constant of the anion of the substrate with the ionized HPCD.

$$
k_{\text {obs }}=\frac{\left(k_{H O}+k_{C D} K_{C D}^{A}[H P C D]\left[\mathrm{OH}^{-}\right]\right.}{1+K_{C D}{ }^{A}[H P C D]}
$$

The rate and equilibrium constants were calculated using eq 2 which have the same mathematical form of eq 1 with $a=k_{\mathrm{OH}}\left[\mathrm{OH}^{-}\right] \quad b=k_{C D} K_{C D}{ }^{A}\left[\mathrm{OH}^{-}\right]$and $c=K_{C D}{ }^{A}{ }^{18}$ The calculated parameters are given in Table 5.

$$
k_{o b s}=\frac{a+b[H P C D]}{1+c[H P C D]}
$$

It can be seen that $K_{C D}{ }^{A}$ is similar to the value obtained for phenyl hydrogen phthalate (29 \pm 5$) \mathrm{M}^{-120}$ which probably means that the inclusion is similar for both compounds, namely with inclusion of the substrate with the aryl ring inside the cavity. We can see in Table 5 that the value of $b$ is indistinguishable from zero at both $\mathrm{OH}^{-}$concentrations indicating that the rate of the reaction of the included substrate is very small.

Considering $b=0$, eq 2 can be rearranged to eq. 3

$$
\frac{1}{k_{o b s}}=\frac{1}{a}+\frac{C}{a}[H P C D]
$$

Table 5. Rate and equilibrium constants calculated from non-linear fitting of the data to equation 2 and from linear regression according to equation 3

\begin{tabular}{lll}
\hline & $\mathrm{pH}=12.80$ & {$[\mathrm{NaOH}]=0.45 \mathrm{M}$} \\
\hline$a$ & $(3.47 \pm 0.09) \times 10^{-4}$ & $(1.37 \pm 0.01) \times 10^{-3}$ \\
$b$ & $4 \times 10^{-12} \pm 0.003$ & $(2 \pm 3) \times 10^{-3}$ \\
$c$ & $48 \pm 16$ & $52 \pm 5$ \\
$1 / a$ & $(28 \pm 1) \times 10^{2}$ & $731 \pm 7$ \\
$c / a$ & $(151 \pm 9) \times 10^{3}$ & $(350 \pm 4) \times 10^{2}$ \\
\hline
\end{tabular}

A plot according to eq. 3 (Figure 3) is linear, confirming the small value of $b=\mathrm{k}_{\mathrm{CD}} \mathrm{K}_{\mathrm{CD}}{ }^{\mathrm{A}}\left[\mathrm{OH}^{-}\right.$ ]. If we assume that $b$ is smaller than $0.1 a$ at the higher HPCD concentration used, we conclude that $\mathrm{k}_{\mathrm{CD}}$ must be smaller that $2 \times 10^{-4} \mathrm{M}^{-1} \mathrm{~s}^{-1}$. 


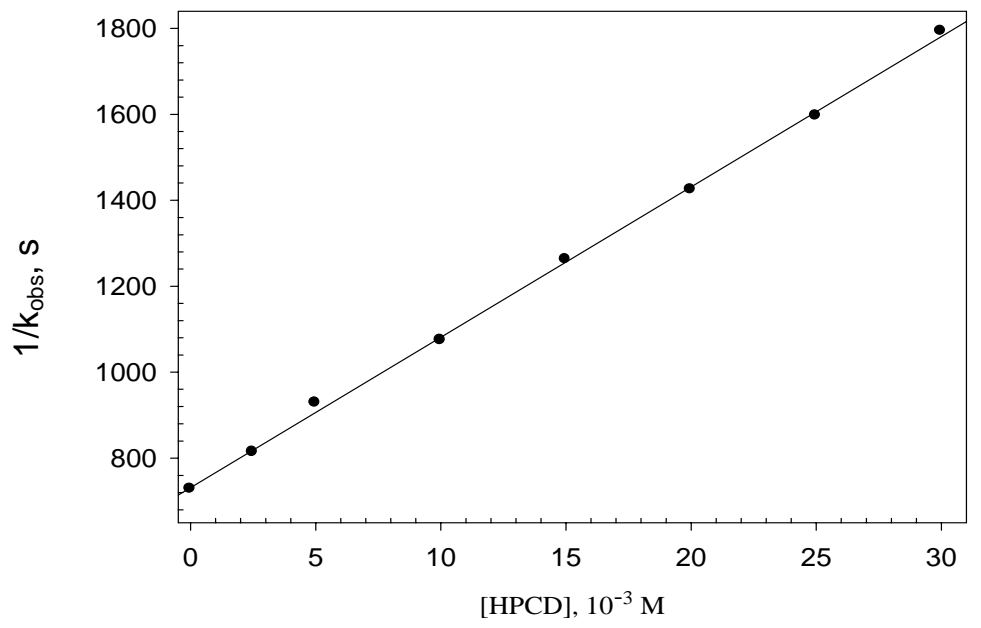

Figure 3. Plot according to eq 3 for the hydrolysis of $\mathbf{1}$ in the presence of HPCD, NaHO=0.45 M.

At least two mechanisms are possible for the step characterized by the rate $\mathrm{k}_{\mathrm{CD}}$ in Scheme 1, these are shown schematically in Schemes 2 and 3.

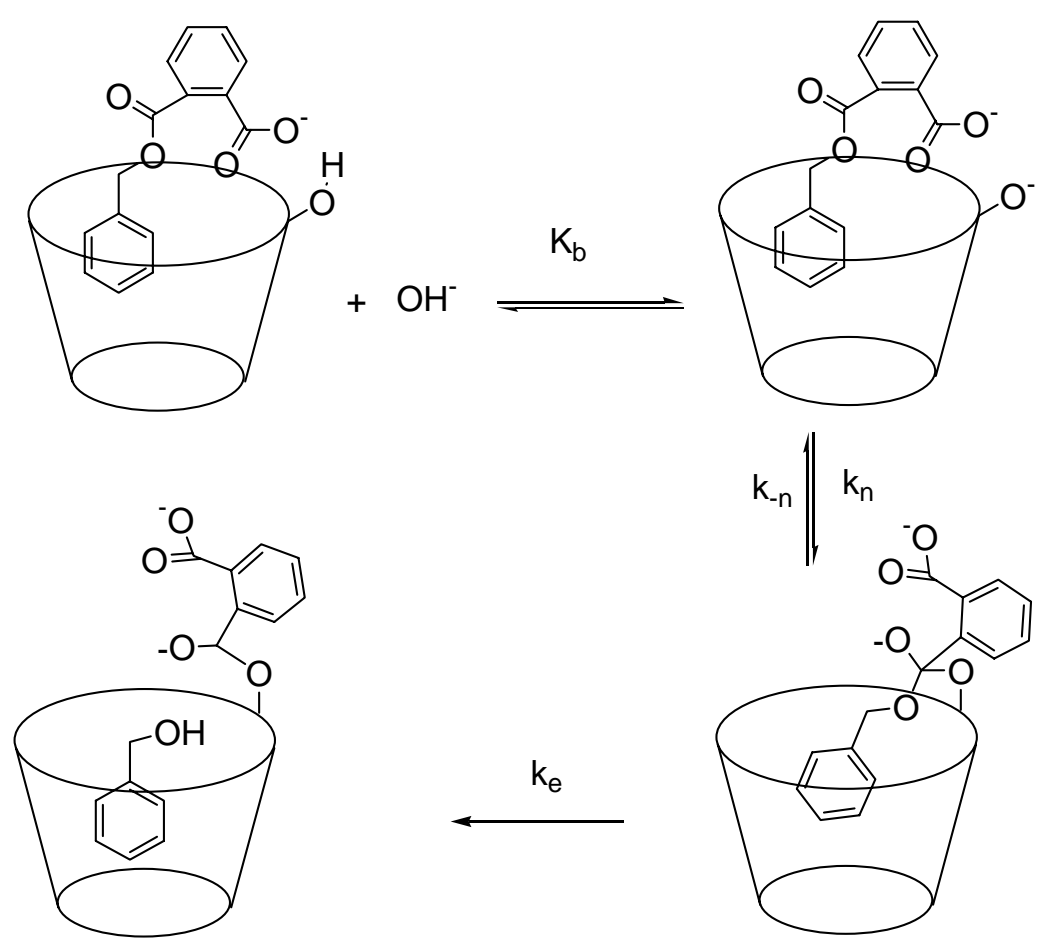

Scheme 2 


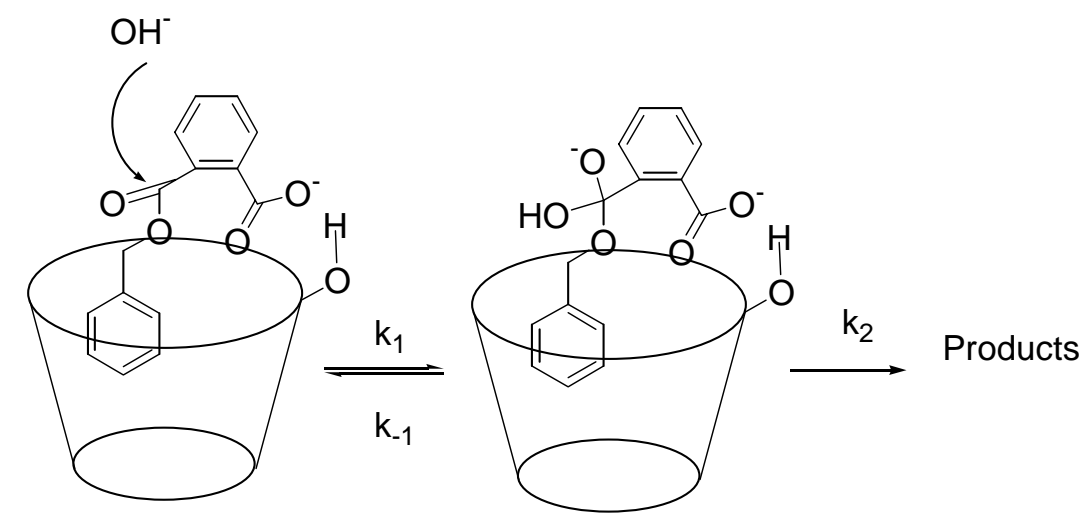

\section{Scheme 3}

The observed rate constant for the cyclodextrin-mediated reaction $\left(k_{C D}\right.$, Scheme 1$)$ is given by eq. 4 for the mechanism described in Scheme 2 .

$$
k_{C D}=K_{b} K_{n} k_{e}
$$

Menger has shown ${ }^{19}$ that the hydrolysis of benzyl acetate is inhibited by $\beta$-cyclodextrin in contrast with that of phenyl acetate that is catalyzed. He explain this result on the bases of a mechanism like that shown in Scheme 2 were $\mathrm{k}_{\mathrm{e}}$ is the rate determining step in the case of a poor leaving group such as benzyl alcohol wile $\mathrm{k}_{\mathrm{n}}$ is the rate determining step for aryl esters.

In order to establish if this is the reason for the inhibition observed in the reaction of substrate 1, we determined the effect of HPCD on the basic hydrolysis of p-chlorophenyl hydrogen phthalate, which has a much better leaving group than 1. As we can see in Figure 4, the rate of hydrolysis of this substrate is also inhibited. The reaction of this substrate has contribution from the intramolecular catalyzed reaction and the $\mathrm{OH}^{-}$catalyzed reaction, but we can subtract the contribution from the intramolecular reaction since we know this rate from previous work. ${ }^{20}$ The results indicate that the reaction of $\mathrm{OH}^{-}$with this ester is also strongly inhibited, therefore we can discard the mechanism described in Scheme 2. The mechanism must be the one shown in Scheme 3 were an external $\mathrm{OH}^{-}$react with the complexed substrate and this reaction is slower than that corresponding to the substrate free in solution.

We suggest that the inhibition observed can be explained if the substrate forms a complex with a structure as shown in Scheme 4. In this complex the carboxylate group form hydrogen bond with an hydroxyl group at the rim of the cyclodextrin cavity. In this complex and the ionized group of cyclodextrin, which is usually responsible for the catalysis in the hydrolysis of esters, is forced to be located far from the reactive carbonyl ester due to electrostatic repulsion,

The attack of hydroxide ion to the reactive carbonyl group of the ester is difficult due to the steric constraint imposed by the cyclodextrin and also for electronic repulsion with the negatively charged oxygen at the rim of the cyclodextrin cavity. The formation of a complex like 
the one shown in Scheme 4 also explain the strong inhibition of the intramolecular catalysis in the reactions of aryl hydrogen phthalates previously reported. ${ }^{20}$

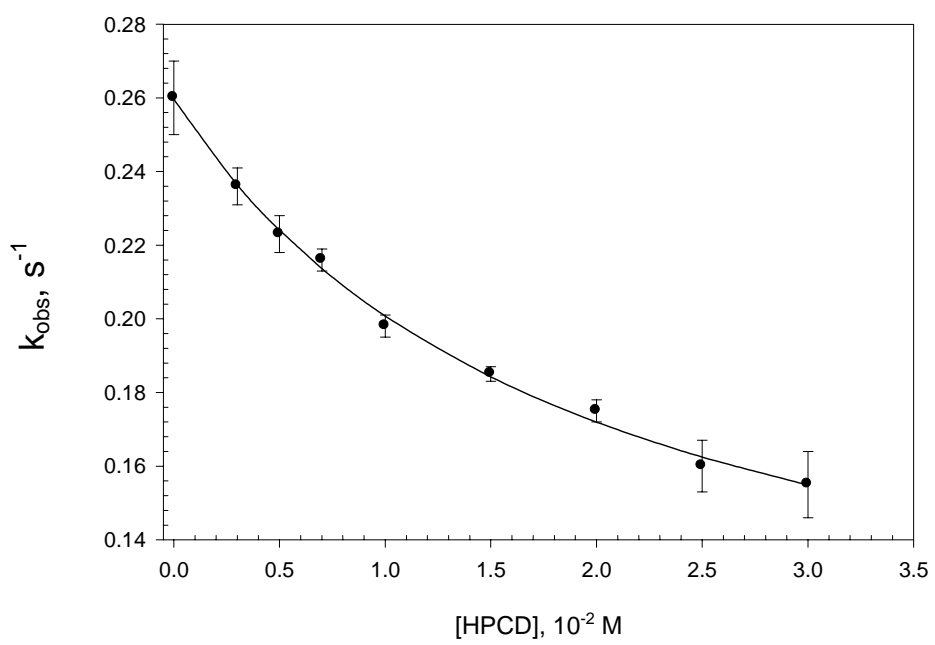

Figure 4. Effect of HPCD on the hydrolysis of p-chlorophenyl hydrogen phthalate at $25^{\circ} \mathrm{C}$, ionic strength $0.5 \mathrm{M} \mathrm{NaHO}=0.45 \mathrm{M}$, acetonitrile $3.85 \%$. The solid line was calculated using eq. 2 with $a=0.260, b=4.6$ and $c=52$.

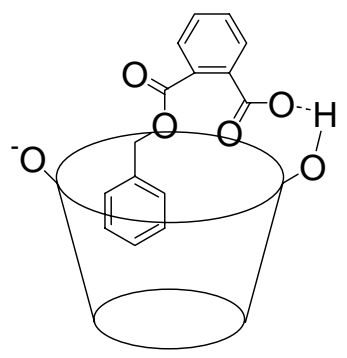

\section{Scheme 4}

\section{Conclusions}

The hydrolysis of benzyl hydrogen phthalate do not show a significant intramolecular catalysis by the ionized carboxylate group and the rate of the base catalyzed hydrolysis is at least two order of magnitude faster than the value calculated using the Brönsted plot defined by aryl hydrogen phthalates. This behaviour is taken as evidence that this substrate react by different mechanism than that of the aryl esters, and therefore it forms a tetrahedral intermediate. On the other hand, the hydrolysis mediated by cyclodextrin is very inefficient due to the structure of the complex of the substrate with the cyclodextrin. We suggest that it has the ionized hydroxyl of the cyclodextrin rim located far from the reactive carbonyl group. The carboxylate group of the 
substrate that is hydrogen bonded to the non-ionized hydroxyl groups of the cyclodextrin forces this group disposition.

\section{Experimental Section}

General Procedures. NMR were determined on a Brucker AC 200 and IR on a Nicolet 5XC spectrometer. Aqueous solutions were made up from water purified in a Millipore apparatus. Acetonitrile Merck HPLC was dried on Silica Gel $10 \%$ p/v as described in the literature. ${ }^{21}$

HPCD (average degree of substitution 5.9, PM 1454) (Roquette) was a gift from Ferromet S.A. Argentina and was used without further purification. The $\mathrm{pH}$ measurements were done at controlled temperature and calibrated with buffers prepared according to the literature. ${ }^{22}$

The benzyl ester was prepared adding phthalic anhydride to a solution of sodium benzyl oxide prepared from the reaction of benzyl alcohol with sodium in anhydrous ethyl ether at room temperature. After $5 \mathrm{hs}$, a $2 \mathrm{M}$ solution of $\mathrm{HCl}$ in ether was added and the product isolated. Yield. $42 \%$, mp 104.4-105.4 $4^{\circ}$ (Lit. 103-104). ${ }^{23}$ The ${ }^{13} \mathrm{C}$ NMR, H NMR and IR are in agreement with the literature data.

Kinetic procedures. The reactions were carried out in the thermostated cell of a conventional spectrophotometer. The substrate dissolved in $100 \mu \mathrm{L}$ of dry acetonitrile was added to $3 \mathrm{~mL}$ of a water solution containing all the other ingredients. The wavelength used to monitor the reactions was: $278 \mathrm{~nm}$

The reactions of Z-aryl hydrogen phthalates were done in a Stopped-Flow apparatus with unequal mixing as reported before. ${ }^{20}$

All reactions were run at $(25.0 \pm 0.1)^{\circ} \mathrm{C}$ and at constant ionic strength $(0.5 \mathrm{M})$ using $\mathrm{NaCl}$ as compensating electrolyte.

\section{Acknowledgements}

This research was supported in part by the Agencia Nacional de Ciencia y Tecnologia, FONCYT, Fundación Antorchas, Consejo Nacional de Investigaciones Científicas y Técnicas (CONICET), the Agencia Cordoba Ciencia and the Universidad Nacional de Córdoba, Argentina. G.O.A. is a grateful recipient of a Fellowship from CONICET.

\section{References}


1. (a) Kirby, A.J.; P. W. Lancaster, P.W. J. Chem. Soc., Perkin 2 1972, 1206. (b) Suh, J; Chun, K.H. J. Am. Chem. Soc. 1986, 108, 305. (c) Menger, F. M; Ladika, M. J. Am. Chem. Soc. 1988, 110, 6794.

2. Aldersley, M. F.; Kirby, A. J.; Lancaster, P. W. J. Chem. Soc., Perkin 2 1974, 1504.

3. (a) Bender, M. L; Komiyama. M. Cyclodextrin Chemistry; Springer-Verlag: New York. 1977. (b) Tabushi, I:; Kuroda. Y. In Advances in Catalysis; Eley, D. D.; Pines, H.; Weisz, P. B., Eds.; Academic Press: London. 1983. Vol. 32, pp 417-462.

4. (a) Takashi, K. Chem. Rev. 1998, 98, 2013. (b) Breslow, R.S.; Dong, S.D. Chem. Rev. 1998, 98, 1997. (c) Viola, L.; de Rossi, R. H. Can. J. Chem. 1999, 77, 860.

5. (a) Hartwell, E.; Hodgson, D. R. W.; Kirby, A. J. J. Am. Chem. Soc. 2001, 122, 9326. (b) Menger, F. M. Acc. Chem. Res. 1985, 18, 128.

6. (a) Kim, Y.; Yoon, M.; Kim, D.J. Photochem Photobiol A Chem. 2001, 138, 167. (b) Vizvardi, K.; Desmet, K.; Luyten, I.; Sandra, P.; Hoornaert, G.; Vander Eycken, E. Org. Lett. 2001, 3, 1173.

7. Andrés, G. O.; Granados, A. M.; de Rossi, R. H. J. Org. Chem. 2001, 66, 7653.

8. Castro, E. A. Chem. Rev. 1999, 99, 3505.

9. The pKa of benzyl alcohol was estimated considering that the phenyl group should decrease the pKa of $\mathrm{MeOH}$ (15.4, see.CRC Handbook of Biochemistry and Molecular Biology, Fasman, G. A. Ed., $3^{\text {rd }}$ Edn, CRC Press: Cleveland, Ohio, 1977) by about the same amount as it decreases the pKa of $\mathrm{MeNH}_{2}$ (10.62). The value reported for benzyl alcohol is 15.2 (Menger, F. M.; Ladika, M. J. Amer. Chem. Soc. 1987, 109, 3145) which seems too high.

10. Kirsch, J. F.; Jencks, W.P J. Am. Chem. Soc. 1964, 86, 837.

11. Ba-Saif, S.; Luthra,A. K ; Williams, A. J. Am. Chem. Soc. 1989, 111, 2647.

12. Guthrie, J. P. J. Am. Chem. Soc. 1991, 113, 3941.

13. Stefanidis, D.; Cho, S.; Dhe-Pagamon, S.; Jencks, W. P. J. Am. Chem. Soc. 1993, 115, 1650.

14. Hengge, A. C; Hess, R. A. J. Am.Chem. Soc. 1994, 116, 11256.

15. Takahashi, K. Chem. Rev. 1998, 98, 2013.

16. Tee, O. S.; Bozzi, M.; Hoeven, J. J.; Gadosy, T. A. J. Am. Chem. Soc. 1993, 115, 8990

17. This is pKa of $\beta$-cyclodextrin reported by Hamai, S. Bull. Chem. Soc. Jpn. 1996, 69, 543. but the pKa of HPCD is not expected to be very different from this value.

18. Sigmaplot 5.0 was used for non-linear fitting and the parameters were $a, b$, and $c$ or we used the experimentally determined value of $a$ and calculated $b$ and $c$. Both methods gave similar results.

19. Menger, F. M.; Ladika, M. J. Amer. Chem. Soc. 1987, 109, 3145

20. Andrés, G.O.; Granados, A.M.; de Rossi, R. H. J. Chem. Soc., Perkin 2 2002, 1502.

21. Perrin, D.D.; Armarego; W. L. G. Purification of Laboratory Chemicals, ButterworthHeinemann Ltd: Great Britain, 3th Edn, 1994; p 68.

22. Lide D. R. Edr, Handbook of Chemistry and Physics CRC Press, 72nd Edn, 1991-1992; p 830 to 8-35.

23. Padwa, A.; Carter, S. P.; Nimmesgern, H.; Stull; P. D. J. Am. Chem. Soc. 1988, 110, 2894. 